\title{
Growth inhibitory efficacy and anti-aromatase activity of Tabebuia avellanedae in a model for post-menopausal Luminal A breast cancer
}

\author{
NITIN TELANG ${ }^{1}$, HAREESH B. NAIR ${ }^{2}$ and GEORGE Y.C. WONG ${ }^{3,4}$ \\ ${ }^{1}$ Cancer Prevention Research Program, Palindrome Liaisons Consultants, Montvale, NJ 07645-1559; ${ }^{2}$ Department of \\ Obstetrics and Gynecology, University of Texas Health Sciences Center, San Antonio, TX 78229; ${ }^{3}$ American Foundation \\ for Chinese Medicine, New York, NY 11103; ${ }^{4}$ Breast Center, Maimonides Medical Center, Brooklyn, NY 11219, USA
}

Received April 25, 2019; Accepted September 10, 2019

DOI: $10.3892 /$ br.2019.1244

\begin{abstract}
Aromatase inhibitors (AIs) represent a treatment option for post-menopausal estrogen receptor-positive $\left(\mathrm{ER}^{+}\right)$breast cancer as monotherapy, or in combination with cyclin-dependent kinase $4 / 6$ or mTOR inhibitors. Long-term treatment with these agents leads to dose-limiting toxicity and drug resistance. Natural substances provide testable alternatives to current therapy. Tabebuia avellanedae (TA) tree is indigenous to the Amazon rainforest. The inner bark of TA represents a medicinal dietary supplement known as Taheebo. Non-fractionated aqueous extract from TA is an effective growth inhibitor in the Luminal A and triple negative breast cancer models. The quinone derivative naphthofurandione (NFD) is a major bioactive agent in TA. The present study examined the efficacy of finely ground powder from the inner bark of TA, available under the name of Taheebo-NFD-Marugoto (TNM). The ER ${ }^{+}$MCF-7 cells stably transfected with the aromatase gene $M C F-7^{A R O M}$ represented a model for aromatase-expressing post-menopausal breast cancer. Anchorage-independent colony formation, cell cycle progression, pro-apoptotic caspase 3/7 activity, apoptosis-specific gene expression, aromatase activity and select estradiol $\left(\mathrm{E}_{2}\right)$ target gene expression represented the mechanistic end points. Treatment of MCF-7 ${ }^{\mathrm{AROM}}$ cells with TNM induced a dose-dependent reduction in $\mathrm{E}_{2}$-promoted anchorage-independent colony number. Mechanistic assays on TNM-treated MCF-7 $7^{\text {AROM }}$ cells demonstrated that TNM at a concentration of $10 \mu \mathrm{g}$ (NFD content: $2 \mathrm{ng}$ ), induced S-phase arrest, increased pro-apoptotic caspase 3/7 activity, increased pro-apoptotic BAX and decreased anti-apoptotic $B C L-2$ gene expression, and inhibited aromatase activity. Additionally,
\end{abstract}

Correspondence to: Dr Nitin Telang, Cancer Prevention Research Program, Palindrome Liaisons Consultants, 10 Rolling Ridge Road, Apt. B, Montvale, NJ 07645-1559, USA

E-mail: ntelang3@gmail.com

Key words: Tabebuia avelanedae, growth inhibition, aromatase inhibition, breast cancer cells
TNM treatment downregulated ESR-1 (gene for ER- $\alpha$ ), aromatase and progesterone gene expression and reduced mRNA levels of $\mathrm{E}_{2}$ target genes $p S 2, G R B 2$ and cyclin D1. Inhibition of aromatase activity, based on the NFD content of TNM was superior to the clinical AIs Letrozole and Exemestane. These data demonstrated the potential efficacy of TNM as a nutritional alternative for current therapy of aromatase positive, post-menopausal breast cancer.

\section{Introduction}

Clinical treatment options for post-menopausal hormone receptor positive, human epidermal growth factor receptor-2 negative breast cancer include the use of selective estrogen receptor modulators and aromatase inhibitors $(1,2)$. Aromatase inhibitor based monotherapy is frequently combined with selective small molecule inhibitors of CDK4/6 and mTOR pathways. Long-term treatment involving single agent therapy or multi-agent combination therapy is frequently associated with acquired drug resistance predominantly due to the emergence of cancer stem cells, thereby impacting therapeutic efficacy and promoting disease progression (3-5).

Aromatase CYP19 A1 functions as a critical enzyme for peripheral and intra-tumoral estrogen bio-synthesis via conversion of adrenal androstenedione to estrone $\left(\mathrm{E}_{1}\right)$ and subsequently to estradiol $\left(\mathrm{E}_{2}\right)$ thereby providing growth-promoting estrogens. Pharmacological agents Letrozole (LET) and Exemestane (EXM) are selective inhibitors of aromatase $(1,2)$. These agents exhibit acquired tumor resistance in preclinical models for aromatase-expressing Luminal A breast cancer, as well as in estrogen receptor-positive clinical breast cancer (6-12).

Naturally occurring non-toxic substances including dietary supplements and natural botanicals are widely used in complementary and alternative medicine. Natural products exhibiting effective inhibition of aromatase activity may represent potential testable alternatives to the limitations of clinical aromatase inhibitors.

Tabebuia avellanedae (TA) is a tree native to the Amazon rainforest. Drinks from the bark of the TA tree have been traditionally used by the indigenous population to address a wide variety of health issues. A non-fractionated powder from 
the inner bark of TA, under the name Taheebo, is available from Taheebo Japan, Co., Ltd.. An aqueous extract of Taheebo has been documented to exhibit anti-cancer activity in animal models for organ site cancers (13), as well as growth inhibitory efficacy in human carcinoma-derived cell culture models for prostate and breast cancer via multiple mechanisms (14-16). Growth inhibitory efficacy of TA extract in a model for Luminal A breast cancer subtypes is associated with the differential expression of proliferation and apoptosis-specific genes (17). In a model for triple-negative breast cancer the inhibitory efficacy of TA is attributable to inhibition of $\mathrm{G}_{1}$ to $\mathrm{S}$ phase transition, induction of pro-apoptotic caspase 3/7 activity and modulation of the RB pathway (18).

Recently, Taheebo Japan invented a proprietary process capable of producing TA powder that is considerably more finely ground than the original TA powder. The new product marketed by Taheebo Japan under the name of Taheebo NFD Marugoto (TNM), is expected to provide superior results to their original Taheebo due to its reduced particle size and greater aqueous solubility.

In an effort to evaluate the growth inhibitory effects and anti-aromatase activity of TNM, the experiments in the present study were designed to i) examine the growth inhibitory efficacy of TNM in a model for aromatase-expressing post-menopausal breast cancer, ii) evaluate the effects of TNM on cellular aromatase activity, and iii) identify possible molecular mechanisms responsible for the efficacy of TNM.

\section{Materials and methods}

Experimental model. The MCF-7 ${ }^{\mathrm{AROM}}$ cell line represented the experimental model for the present study. These $\mathrm{ER}^{+} / \mathrm{PR}^{+} / \mathrm{HER}-2^{-}$human mammary carcinoma-derived cells, stably transfected with the aromatase gene $(6,10)$, possess the characteristics of aromatase-expressing, post-menopausal Luminal A molecular subtype of clinical breast cancer.

\section{Test compounds}

Taheebo NFD Marugoto (TNM). This compound is comprised of finely ground powder from the inner bark of TA tree containing the bioactive agent Naphthofurandione (NFD) was provided by Taheebo Japan Co., Ltd.. The non-fractionated aqueous stock solution was prepared following the protocol provided by the supplier. This stock solution of TNM contains $200 \mathrm{ng}$ of NFD (Personal Communication: Dr Fukuda, Taheebo Japan). The stock solution was serially diluted in the culture medium to obtain final concentrations of TNM for the dose response experiments, and to identify minimally effective, half maximal $\left(\mathrm{IC}_{50}\right)$ and maximally cytostatic $\left(\mathrm{IC}_{90}\right)$ concentrations that were used for the mechanistic assays.

Letrozole (LET). Stock solution of LET (molecular mass: $285 \mathrm{kDa}$, Sigma-Aldrich; Merck KGaA) was prepared in DMSO and serially diluted in the culture medium to obtain the final concentration of $1 \mu \mathrm{M}(285 \mathrm{ng})$.

Exemestane (EXM). Stock solution of EXM (molecular mass: 296 kDa, Sigma-Aldrich; Merck KGaA) was prepared in DMSO and was serially diluted in the culture medium to obtain the final concentration of $10 \mu \mathrm{M}(2,960 \mathrm{ng})$.
LET and EXM represent the prototypical aromatase inhibitors. The concentrations of $1 \mu \mathrm{M}$ LET and $10 \mu \mathrm{M}$ EXM are comparable to the effective concentrations traditionally used in the cell culture experiments, and represent clinically achievable effective concentrations. These compounds were used as positive controls for the present experiments.

Anchorage-independent growth. For this assay the stock solution of agar was prepared by mixing DNA grade agar (Sigma-Aldrich; Merck KGaA) with an appropriate volume of 2X RPMI-1640 medium. To prepare the basement layer, this stock solution was diluted to $0.6 \%$, dispersed in a 6 -well plate and allowed to solidify overnight at $37^{\circ} \mathrm{C}$. Suspension of MCF-7 $7^{\text {AROM }}$ cells, at a density of $5 \times 10^{5}$ per ml, was prepared in RPMI-1640 medium containing $0.33 \%$ agar, and this cell suspension was overlaid on the basement layer in the presence or absence of TNM. The cultures were incubated at $37^{\circ} \mathrm{C}$ in a $\mathrm{CO}_{2}$ incubator for 21 days. The anchorage-independent (AI) colonies were stained with $0.005 \%$ crystal violet and colony counts were determined at $\times 10$ magnification. The data were expressed as number of AI colonies.

Cell cycle progression. For the cell cycle analysis, $5 \times 10^{5}$ cells were seeded in T-25 flasks and treated for $24 \mathrm{~h}$. post-seeding with 1,5 and $10 \mu \mathrm{g}$ of TNM for $48 \mathrm{~h}$. The cells were harvested by trypsinization, pelleted at $500 \mathrm{x}$ g, and washed twice with cold PBS (Sigma-Aldrich; Merck KGaA). The cells were then fixed with cold $70 \%$ ethanol, washed with cold PBS, and stained with propidium iodide (PI, $50 \mu \mathrm{g} / \mathrm{ml}$, Sigma-Aldrich; Merck KGaA, in PBS), followed by the addition of ribonuclease $(10 \mu \mathrm{g} / \mathrm{ml}$, Sigma-Aldrich; Merck KGaA) and incubation for $4 \mathrm{~h}$ in the dark. The cell cycle analysis was performed at the Core Facility of the University of Texas Health Sciences Center (San Antonio), using optimized protocols that included i) sorting of PI-stained cells, ii) use of a $488 \mathrm{~nm}$ excitation filter and a $520 \mathrm{~nm}$ band pass filter, and iii) gating of fluorescent events on forward versus side scatter. Cell cycle progression was monitored using a Becton Dickinson FACSCAN flow cytometer (BD Biosciences), and the data were analyzed using FACS Express software (De Novo Software). The data were expressed as a percentage of cells in $\mathrm{G}_{1}, \mathrm{~S}$ and $\mathrm{G}_{2}$ phases of the cell cycle.

Caspase activity. Caspase $3 / 7$ activity in the MCF-7 ${ }^{\mathrm{AROM}}$ cells was measured using caspase-Glo assay kit (Promega). Briefly, the cells treated with TNM were homogenized by sonication in homogenization buffer (25 mmol/1 HEPES, pH 7.5, $5 \mathrm{mmol} / 1$ $\mathrm{MgCl}_{2}$, and $1 \mathrm{mmol} / \mathrm{l}$ EGT) and protease inhibitors (all from Sigma-Aldrich; Merck KGaA). The homogenate was centrifuged at $6,500 \mathrm{x} \mathrm{g}$ at $4^{\circ} \mathrm{C}$ for $15 \mathrm{~min}$, and the supernatant was collected. Subsequently, $10 \mu \mathrm{l}$ of assay reagent was added to $10 \mu \mathrm{l}$ of supernatant and the reaction mixture was incubated at room temperature for $2 \mathrm{~h}$. Resulting luminescence was measured using a Fluoroskan Luminometer (Thermo Scientific Co.). The data were expressed as relative luminescent units (RLU).

Gene expression profiling. The effect of TNM on the expressions of apoptosis regulatory genes $B A X$ and $B C L-2$, $\mathrm{E}_{2}$ regulatory target genes $E S R-1, A R O M$ and $\mathrm{PR}$ and $\mathrm{E}_{2}$ responsive target genes $p S 2, G R B-2$ and cyclin $D 1$ was examined using reverse transcription quantitative PCR (RT-qPCR) 
Table I. Primer sets used for reverse transcription-quantitative PCR analysis.

\begin{tabular}{ll}
\hline Gene name & \multicolumn{1}{c}{ Primer sequence } \\
\hline ESR-1 & 5'-TGTGCAATGACTATGCTTCA-3' (S) \\
& 5'-GCTCTTCCTCCTGTTTTTA-3' (AS) \\
AROM & 5'-AGCATGCTGTACCAGCCTGT-3' (S) \\
& 5'-TCATCATCACCATGGCCATGT-3' (AS) \\
$P R$ & 5'-ACAGAATTCATGAGCCGGTCCGGG \\
& TGCAAG-3' (S) \\
& 5'ACAAGATCTCCACCCAGAGCCCG \\
& AGGTTT-3' (AS) \\
pS2 & 5'-CATCGACGTCCCTCCAGAAGAG-3' (S) \\
& 5'-CTCTGGGACTAATCACCGTGCTG-3' (AS) \\
GRB2 & 5'-AAATGCTCAGCAAACAGCGG-3' (S) \\
& 5'-TGAAGTGCTGCACATCATTTCC-3' (AS) \\
Cyclin D1 & 5'-ACGAAGGTCTGCGCGTGTT-3' (S) \\
& 5'-CCGCTGGCCATGAACTACCT-3' (AS) \\
BCL-2 & 5'-CCTGTGGATGACTGAGTACC-3' (S) \\
& 5'-GAGACAGCCAGGAGAAATCA-3' (AS) \\
BAX & 5'-GTTTCATCCAGGATCGAGCAG-3' (S) \\
& 5'-CATCTTCTTCCAGATGGTGA-3' (AS) \\
$\beta$-actin & 5'-GACCTCTATGCCAACACAGT-3' (S) \\
& 5'-AGTACTTGCGCTCAGGAGGA-3' (AS) \\
\hline
\end{tabular}

assay following published protocols (19). Briefly, RNA from TNM treated and untreated control cells was isolated using the RNeasy plus kit (Qiagen Inc.), with a genomic DNA removal step as per the manufacturer's protocol. Reverse transcription (RT) was carried out using the Applied Biosystems kit (Applied Biosystems). RT-qPCR and subsequent analyses were carried out using Smart Mix PCR beads (Cepheid) with 0.25X SYBR-Green in the Cepheid Smart Cycler to detect indicated $\mathrm{E}_{2}$ target genes and the housekeeping gene $\beta$-actin transcripts, representing normalization control. Melt curve analysis was performed after each RT-qPCR cycle to ascertain PCR product specificity. PCR reactions of the indicated primer sets for $\mathrm{E}_{2}$ target genes and for $\beta$-actin primer sets gave unique melt peaks, indicative of discrete amplification products. Reaction mix (25 $\mu \mathrm{l})$ was prepared containing $\mathrm{MgCl}_{2}(2 \mathrm{mmol} / \mathrm{l}), 12.5 \mu \mathrm{l}$ of 2X Taq PCR Master Mix (Qiagen, Inc.), 0.25X SYBR-Green (Fisher Scientific Co.) and gene-specific primer sets $(0.3 \mu \mathrm{mol} / \mathrm{l}$ each, obtained from the Core Facility, University of Texas). The PCR reaction was set for 40 cycles, and the data were compared after normalization with $\beta$-actin RNA levels. RT-qPCR assays were performed in duplicate and repeated at least three times. These data were expressed as $\Delta \Delta \mathrm{Cq}$ values for quantification of relative gene expression (20). The primer sequences for the sense (S) and anti-sense (AS) strands for ESR-1 (gene for ER- $\alpha$ ), AROM, PR, pS2, GRB2, cyclin D1, BCL-2, BAX and $\beta$-actin genes are represented from $5^{\prime}$ to $3^{\prime}$ (Table I).

Aromatase activity. To measure aromatase enzymatic activity, the ${ }^{3} \mathrm{H}_{2} \mathrm{O}$ release assay was used. $\left[{ }^{3} \mathrm{H}\right]$ androstenedione represented

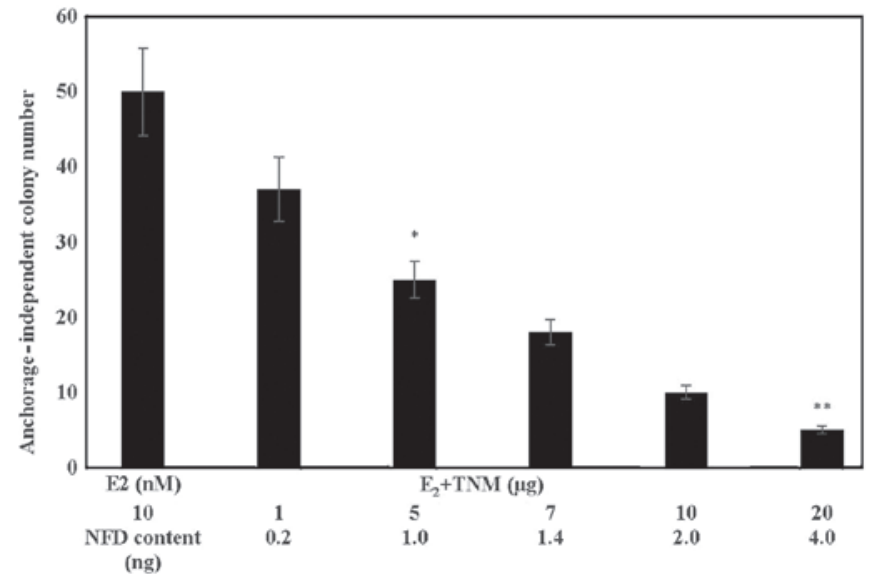

Figure 1. Effect of Taheebo NFD Marugoto (TNM) on anchorage-independent growth in MCF-7 ${ }^{\text {AROM }}$ cells. TNM treatment exhibited a dose-dependent decrease in the number of anchorage-independent colonies. TNM IC $50.5 \mu \mathrm{g}$ $(\alpha=0.05) ; \mathrm{IC}_{90} 20 \mu \mathrm{g}^{* *}(\alpha=0.05)$ vs. $\mathrm{E}_{2}$-treated control. Results were presented as mean anchorage-independent colony number $\pm \mathrm{SD}, \mathrm{n}=4$ per treatment group. Data were analyzed by ANOVA and Dunnett's test. $\mathrm{E}_{2} ; 17 \beta$-estradiol, TNM, Taheebo NFD Marugoto; NFD; naphthofurandione, SD, standard deviation; ANOVA; analysis of variance.

the substrate and its conversion to $E_{1}$ represented a measure for aromatase activity. The MCF-7 $7^{\mathrm{AROM}}$ cells grown in phenol-free RPMI-1640 medium supplemented with charcoal-stripped fetal bovine serum (Sigma-Aldrich; Merck KGaA) were suspended in an assay mixture containing $0.1 \%$ bovine serum albumin, $67 \mathrm{mmol} / 1 \mathrm{KPO}_{4}(\mathrm{pH} 7.4)$, and $2.0 \mu \mathrm{mol} / \mathrm{l}$ progesterone. After sonication, $100 \mathrm{nmol} / 1$ of $\left[{ }^{3} \mathrm{H}\right]$ androstenedione $(25.3 \mathrm{ci} / \mathrm{mmol}$, NET-962; Perkin-Elmer, Inc.) was added and the mixture was incubated for $10 \mathrm{~min}$ at room temperature. NADPH was then added to a final concentration of $1.2 \mathrm{mmol} / 1$, followed by $37^{\circ} \mathrm{C}$ incubation and the addition of an equal volume of 5\% trichloroacetic acid. The supernatant was collected and extracted with an equal volume of chloroform. Dextran-coated charcoal was added to the assay mixture, which was then vortexed and centrifuged at $6,500 \mathrm{x} \mathrm{g}$ at $40^{\circ} \mathrm{C}$ for $15 \mathrm{~min}$. The supernatant was then added to scintillation fluid and measured in a scintillation counter (Perkin-Elmer). The data were expressed as $\mathrm{f}$ mole $\mathrm{E}_{1}$ formed, per mg protein, per hour (21).

Statistical analysis. The experiments for dose response using the anchorage-independent growth assay were conducted in quadruplicate. Experiments for cell cycle progression, caspase 3/7 activity, aromatase activity and gene expression profiling were conducted in triplicate. The data were expressed as mean \pm SD. Statistically significant differences between the control and treatment groups were assessed by the two-sample Student's t-test. $\mathrm{P}<0.05$ was considered to indicate a statistically significant difference. Additionally, data from comparisons of multiple treatment groups were analyzed using analysis of variance (ANOVA) and Dunnett's test as a post-hoc test with a threshold of $\alpha=0.05$ (Microsoft Excel 2013 XLSTAT-Base software).

\section{Results}

Effect of TNM on anchorage-independent growth. The data presented in Fig. 1 show a TNM dose-dependent reduction in the number of $E_{2}$ promoted anchorage-independent colonies. 
Table II. Inhibition of cell cycle progression by TNM in MCF-7 $7^{\text {AROM }}$ cells.

\begin{tabular}{lcccc}
\hline & \multicolumn{4}{c}{ Cell cycle phase } \\
\cline { 3 - 5 } Treatment & Concentration $(\mu \mathrm{g})$ & $\% \mathrm{G}_{1}$ & $\% \mathrm{~S}$ & $\% \mathrm{G}_{2}$ \\
\hline Control & - & $63.2 \pm 1.5$ & $26.2 \pm 0.6^{\mathrm{a}}$ & $9.1 \pm 0.5$ \\
TNM & 10 & $50.2 \pm 1.6$ & $42.5 \pm 0.5^{\mathrm{b}}$ & $6.7 \pm 0.4$ \\
$\Delta$ control & & $-20.6 \%$ & $+63.2 \%$ & $-26.4 \%$
\end{tabular}

Results were expressed as mean $\pm \mathrm{SD}, \mathrm{n}=3$ per treatment group. ${ }^{\mathrm{a}, \mathrm{b}} \mathrm{P}=0.04$. Data were analyzed by two-sample Student's t-test. TNM, Taheebo NFD Marugoto; SD, standard deviation.
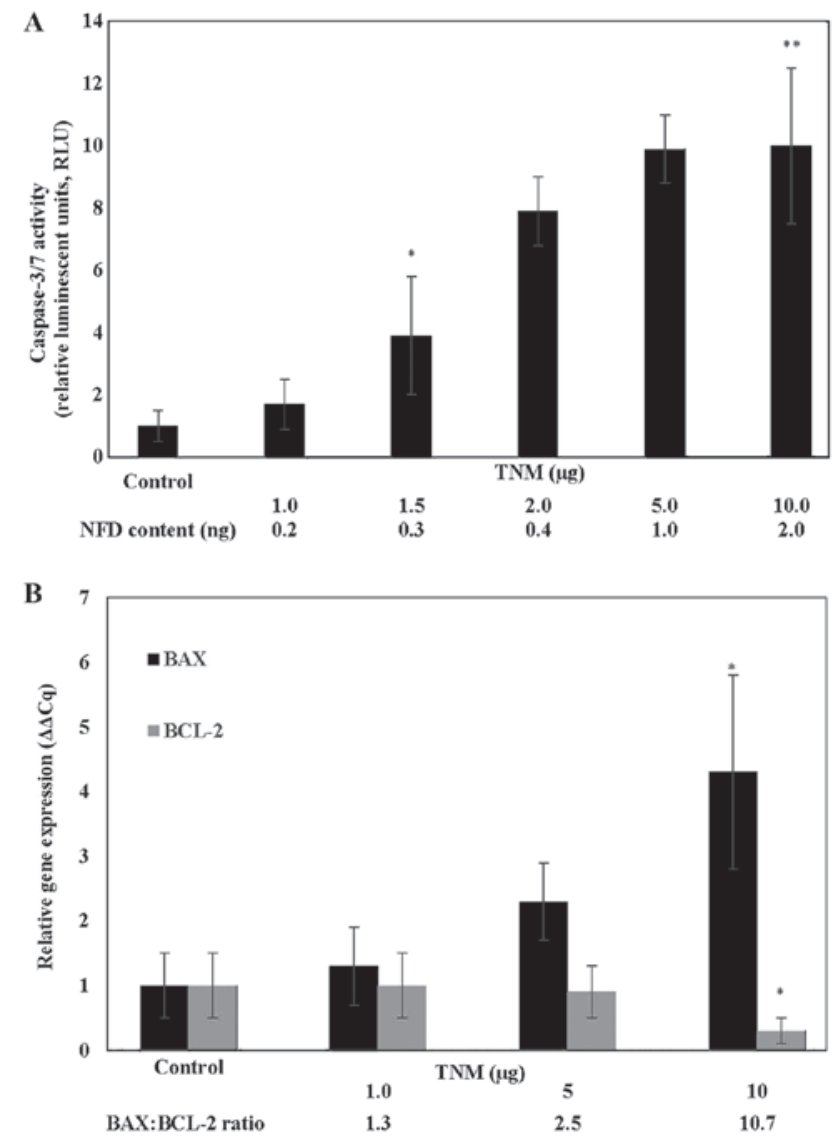

Figure 2. (A) Induction of caspase activity by Taheebo NFD Marugoto (TNM) in MCF-7 $7^{\text {AROM }}$ cells. Treatment with TNM results in a dose-dependent increase in caspase 3/7 activity. Results were presented as RLU mean $\pm \mathrm{SD}$, $\mathrm{n}=3$ per treatment group. Data were analyzed by ANOVA and Dunnett's test. Untreated control $<1.5 \mu \mathrm{g} \mathrm{TNM}{ }^{*}$, untreated control $<10 \mu \mathrm{g} \mathrm{TNM}^{* *}(\alpha=0.05)$. TNM; Taheebo NFD Marugoto, NFD, naphthofurandione, RLU, relative luminescent units; SD, standard deviation; ANOVA, analysis of variance. (B) Modulated expression of apoptosis-specific genes in MCF-7 ${ }^{\text {AROM }}$ cells by Taheebo NFD Marugoto (TNM). Treatment with TNM results in upregulated expression of $B A X$ and downregulated expression of $B C L-2$ genes. Results are presented as relative gene expression $(\Delta \Delta \mathrm{Cq})$ mean $\pm \mathrm{SD}, \mathrm{n}=3$ per treatment group. Data were analyzed by two-sample Student's t-test. BAX: ${ }^{*} \mathrm{P}=0.01$ vs. untreated control. BCL-2: ${ }^{*} \mathrm{P}=0.02$ vs. untreated control. TNM Taheebo NFD Marugoto, BAX; BCL-2 associated X protein; BCL-2; B cell lymphoma-2; SD, standard deviation.

These data identified the $\mathrm{IC}_{50}$ as $5 \mu \mathrm{g}$ TNM $(\alpha=0.05)$, and $\mathrm{IC}_{90}$ as $20 \mu \mathrm{g}$ TNM $(\alpha=0.05)$, relative to the $\mathrm{E}_{2}$-treated controls. The

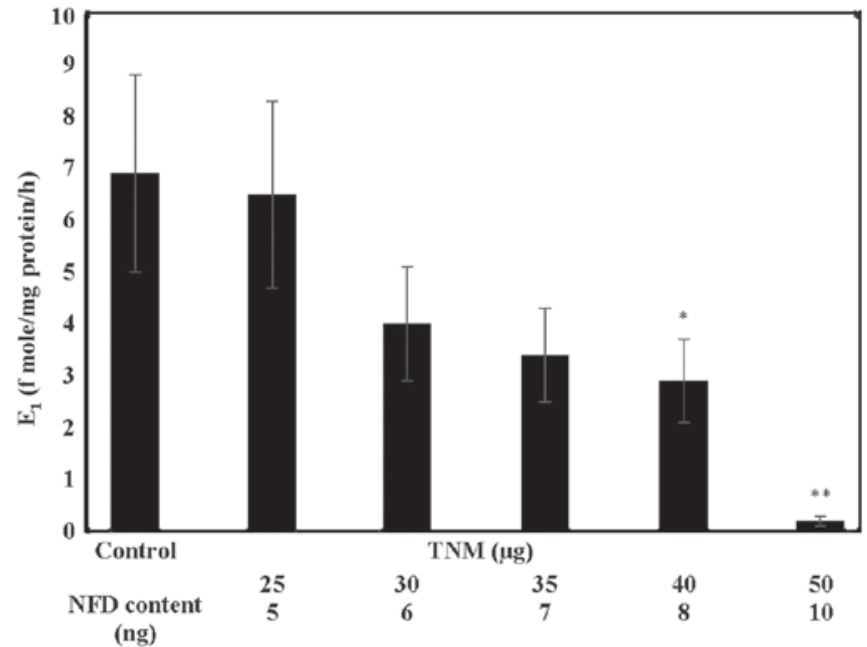

Figure 3. Inhibition of aromatase activity by Taheebo NFD Marugoto (TNM) in MCF-7 ${ }^{\text {AROM }}$ cells. Treatment with TNM results in a dose-dependent inhibition of aromatase activity. Results were presented as $\mathrm{E}_{1}$ formed (f mole/mg protein $/ \mathrm{h}$ ) mean $\pm \mathrm{SD}, \mathrm{n}=3$ per treatment group. Untreated control $>40 \mu \mathrm{g} \mathrm{TNM}(\alpha=0.05)$, untreated control $>50 \mu \mathrm{g} \mathrm{TNM}^{* *}(\alpha=0.05)$. Data were analyzed by ANOVA and Dunnett's test. TNM, Taheebo NFD Matugoto; NFD, naphthofurandione; $\mathrm{E}_{1}$; estrone, ANOVA, analysis of variance; SD, standard deviation.

NFD content of TNM at these concentrations was estimated to be 1.0 and $4.0 \mathrm{ng}$, respectively.

Effect of TNM on cell cycle progression. The data presented in Table II examined the effect of TNM on the cell cycle progression of MCF-7 $7^{\text {AROM }}$ cells. TNM at the maximum cytostatic concentration of $10 \mu \mathrm{g}$ resulted in $62.2 \%$ of cells arrested in the $\mathrm{S}$ phase of the cell cycle $(\mathrm{P}=0.04)$, relative to the untreated control. The inhibition in the $\mathrm{G}_{1}$ and $\mathrm{G}_{2}$ phases were modest and statistically non-significant.

Induction of pro-apoptotic activity by TNM. The induction of cellular apoptosis by treatment with TNM was examined by monitoring the status of caspase $3 / 7$ activity. In response to treatment with TNM, caspase $3 / 7$ activity exhibited a dose-dependent increase (Fig. 2A). Thus, relative to the untreated control, TNM at $1.5 \mu \mathrm{g}, 5 \mu \mathrm{g}$ and $10 \mu \mathrm{g}$ exhibited a 2.9-fold $(\alpha=0.05)$, an 8.9-fold $(\alpha=0.05)$ and a 9 -fold $(\alpha=0.05)$ increase in caspase $3 / 7$ activity, respectively.

At the molecular level, TNM treatment resulted in a dose-dependent increase in pro-apoptotic BAX and a reciprocal decrease in anti-apoptotic $B C L-2$ gene expression. Thus, treatment with $10 \mu \mathrm{g}$ TNM resulted in a 3.3-fold increase $(\mathrm{P}=0.01)$ in the pro-apoptotic BAX and a $70 \%$ decrease $(\mathrm{P}=0.02)$ in the anti-apoptotic $B C L-2$ expression, relative to the respective untreated controls. This reciprocal modulation in the expression of apoptosis-specific genes resulted in an increased BAX: BCL-2 ratio (Fig. 2B).

Inhibition of aromatase activity by TNM. In response to treatment with TNM, MCF-7 ${ }^{\text {AROM }}$ cells exhibited dose-dependent inhibition in aromatase activity as measured by the extent of conversion of androstenedione to $\mathrm{E}_{1}$. Thus, TNM treatment at 30,40 and $50 \mu \mathrm{g}$ resulted in a $42 \%(\alpha=0.05)$, a $57.9 \%(\alpha=0.05)$ and a $97.1 \%(\alpha=0.05)$ decrease in the aromatase activity, relative to the untreated control (Fig. 3). 
Table III. Comparative efficacy for aromatase inhibition by TNM and LET in MCF-7 ${ }^{\text {AROM }}$ cells.

\begin{tabular}{lccc}
\hline Treatment & Concentration & Aromatase activity $\left(\mathrm{E}_{1}\right.$ fmole/mg protein/h) & Inhibition $(\%$ control $)$ \\
\hline Control & - & $6.9 \pm 0.4^{\mathrm{a}}$ & - \\
TNM $(40 \mu \mathrm{g})$ & $8 \mathrm{ng}$ NFD & $2.5 \pm 0.1^{\mathrm{b}}$ & 63.8 \\
LET $(1 \mu \mathrm{M})$ & $285 \mathrm{ng}$ & $2.6 \pm 0.1^{\mathrm{b}}$ & 62.3 \\
\hline
\end{tabular}

Results were expressed as mean $\pm \mathrm{SD}, \mathrm{n}=3$ per treatment group. ${ }^{\mathrm{a}, \mathrm{b}} \mathrm{P}=0.04$. Data were analyzed by the two-sample Student's t-test. $\mathrm{E}_{1}$, estrone; TNM, Taheebo NFD Marugoto; LET, Letrozole; NFD, naphthofurandione; SD, standard deviation.

Table IV. Comparative efficacy for aromatase inhibition by TNM and EXM in MCF-7 ${ }^{\text {AROM }}$ cells.

\begin{tabular}{lccc}
\hline Treatment & Concentration & Aromatase Activity $\left(\mathrm{E}_{1}\right.$ fmole/mg protein/h) & Inhibition $(\%$ control) \\
\hline Control & - & $6.9 \pm 0.30^{\mathrm{a}}$ & - \\
TNM $(100 \mu \mathrm{g})$ & $20 \mathrm{ng}$ NFD & $0.1 \pm 0.08^{\mathrm{b}}$ & 98.5 \\
EXM $(10 \mu \mathrm{M})$ & $2,960 \mathrm{ng}$ & $0.2 \pm 0.10^{\mathrm{b}}$ & 97.1 \\
\hline
\end{tabular}

Results were expressed as mean $\pm \mathrm{SD}, \mathrm{n}=3$ per treatment group. ${ }^{\mathrm{a}, \mathrm{b}} \mathrm{P}=0.01$. Data were analyzed by two-sample Student's t-test. $\mathrm{E}_{1}$, estrone; TNM, Taheebo NFD Marugoto; EXM, exemestane; NFD, naphthafurandione; SD, standard deviation.

Comparative inhibition of aromatase activity by TNM, LET and EXM. The comparative efficacy of TNM and LET for inhibition of aromatase activity revealed that the extent of inhibition of $63.8 \%(\mathrm{P}=0.04)$ by $40 \mu \mathrm{g}$ TNM (NFD content $8 \mathrm{ng})$ was essentially similar to $62.3 \%$ inhibition $(\mathrm{P}=0.04)$ induced by $285 \mathrm{ng}(1 \mu \mathrm{M})$ of LET, relative to the untreated control (Table III).

The comparative efficacy of TNM and EXM for inhibition of aromatase activity is presented in Table IV. These data revealed that the extent of inhibition of $98.5 \%(\mathrm{P}=0.01)$ by $100 \mu \mathrm{g}$ TNM (NFD content $20 \mathrm{ng}$ ) was essentially similar to $97.1 \%$ inhibition $(\mathrm{P}=0.01)$ induced by $2,960 \mathrm{ng}(10 \mu \mathrm{M})$ of EXM, relative to the untreated control.

Inhibition of $E_{2}$ regulated target gene expression by TNM. The data obtained from the effect of TNM on the expression of ESR-1 (gene for ER- $\alpha$ ), AROM and PR genes are presented in Fig. 4A. The extent of inhibition at $10 \mu \mathrm{g}$ of TNM for ESR-1 was $90 \%(\mathrm{P}=0.01)$, for $A R O M$ it was $61 \%(\mathrm{p}=0.04)$ and for $\mathrm{PR}$ it was $61 \%(\mathrm{P}=0.04)$. Thus, treatment with TNM resulted in substantial downregulated expressions of select genes that are regulated by $\mathrm{E}_{2}$.

Inhibition of $E_{2}$ responsive target gene expression by TNM. The data shown in Fig. 4B examined the effect of TNM on the expression of select $\mathrm{E}_{2}$ responsive genes. The extent of inhibition at $10 \mu \mathrm{g}$ of TNM for $\mathrm{pS} 2$ was $62 \%(\mathrm{P}=0.04)$, for GRB2 it was $61 \%(\mathrm{P}=0.04)$, and for cyclin $\mathrm{D} 1$ it was $82 \%(\mathrm{P}=0.01)$. Thus, TNM treatment resulted in a substantial downregulation of $\mathrm{E}_{2}$ responsive gene expressions.

\section{Discussion}

Metastatic breast cancer is a leading cause of cancer related mortality for women in the USA (22). The ER- $\alpha$ positive, aromatase-expressing Luminal A subtype of post-menopausal breast cancer responds to aromatase inhibitors $(6,10)$. However, long-term therapy is frequently associated with acquired resistance that negatively impacts efficacy and facilitates disease progression.

In addition to the present MCF-7 $7^{\text {AROM }}$ model, other cellular models stably transfected with the aromatase gene have been developed from human mammary carcinoma derived MCF-7 and T47D cell lines. These models have been utilized to examine the effects of aromatase inhibitors and investigate the mechanisms responsible for resistance to AI-based endocrine therapy. For example, MCF-7 $7^{\text {AROM }}$ cells have exhibited resistance to Fluvestrant and cross resistance to Letrozole, Anastrazole, Exemestane (9) and T47D AROM cells have exhibited resistance to Letrozole and sensitivity to anti-progestin (23). Additionally, AI resistance has been documented to involve the upregulated expression of HER-2 (10). Collectively, these three cellular models offer valuable experimental approaches to identify efficacious aromatase inhibitors and also to investigate molecular mechanisms responsible for acquired resistance to aromatase nihibitors.

Non-toxic natural nutritional products may represent testable alternatives for endocrine therapy-resistant post-menopausal breast cancer $(17,18,28-31)$, and thereby, may provide treatment options against the clinical limitations of current aromatase inhibitor-based therapy $(2,3,6,9,10)$. Two species belonging to the Tabebuia genus have documented anti-cancer activity. The anti-cancer effects of $T$. avellanedae and T. chrisantha are documented in preclinical xeno-transplant models (13) and in mice carrying Ehrilch ascites tumor (24). The use of TA in traditional medicine is not well documented. However, the effect of an aqueous extract of TA has been examined on the status of quality of life in patients with multiple organ site cancers that are at advanced metastatic stages (25). Additionally, the effects of the TA quinone NFD have been 

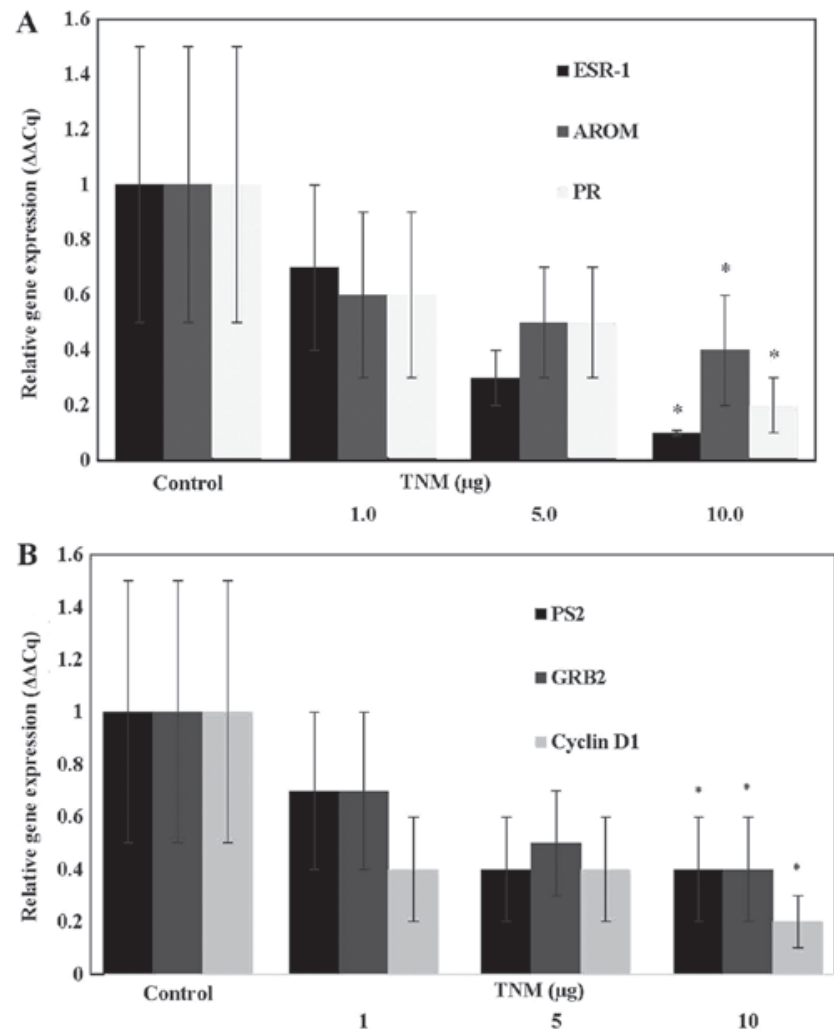

Figure 4. (A) Inhibition of estrogen regulated gene expression by Taheebo NFD Marugoto (TNM) in MCF-7 $7^{\mathrm{AROM}}$ cells. Treatment with TNM results in down-regulated expression of ESR-1, AROM and PR genes. Results were expressed as relative gene expression mean $(\Delta \Delta \mathrm{Cq}) \pm \mathrm{SD}, \mathrm{n}=3$ per treatment group. ESR-1: Untreated control $>10 \mu \mathrm{g} \mathrm{TNM}^{*}(\alpha=0.05)$, AROM: untreated control $>10 \mu \mathrm{g} \mathrm{TNM}^{*}(\alpha=0.05)$, PR: untreated control $>10 \mu \mathrm{g} \mathrm{TNM}(\alpha=0.05)$. Data were analyzed by ANOVA and Dunnett's test. TNM, Taheebo NFD Marugoto; ESR-1, gene for ER- $\alpha$. (B) Inhibition of estrogen responsive gene expression by Taheebo NFD Marugoto (TNM) in MCF-7 $7^{\text {AROM }}$ cells Treatment with TNM results in downregulated expression of $P S 2, G R B 2$ and cyclin D1 gene. Results were presented as relative gene expression $(\Delta \Delta \mathrm{Cq})$ mean $\pm \mathrm{SD}, \mathrm{n}=3$ per treatment group. PS2: Untreated control $>10 \mu \mathrm{g} \mathrm{TNM}^{*}$ $(\alpha=0.05)$, GRB2: Untreated control $>10 \mu \mathrm{g} \mathrm{TNM}^{*}$, cyclin D1: Untreated control $>10 \mu \mathrm{g}$ TNM$^{*}$. Data were analyzed by ANOVA and Dunnett's test. ESR-1: gene for estrogen receptor- $\alpha$, AROM, aromatase; PR; progesterone, SD, standard deviation; TNM, Taheebo NFD Marugoto; PS2, estrogenresponsive gene; GRB2, growth factor receptor binding protein 2; ANOVA, analysis of variance; $\mathrm{SD}$, standard deviation.

documented on head and neck cancer and on a patient with lung metastasis (26).

Experiments in the present study were designed to examine the growth inhibitory efficacy of a non-fractionated aqueous extract from TNM on a cellular model for aromatase-expressing Luminal A subtype of post-menopausal breast cancer.

The ER- $\alpha$-positive human mammary carcinoma-derived MCF-7 cell line is dependent on $\mathrm{E}_{2}$ for anchorage-independent growth in vitro and tumor development in vivo. These in vitro and in vivo end points exhibit a strong positive correlation (27). Thus, the in vitro endpoint that determines the number of AI colonies is a surrogate end point biomarker for cancer risk. $\mathrm{E}_{2}$ promoted anchorage-independent colony number was reduced in response to the treatment with TNM in MCF-7 ${ }^{\mathrm{AROM}}$ cells. In this context, it is noteworthy that several mechanistically distinct nutritional herbs have demonstrated inhibitory effects on anchorage-independent colony formation in MCF-7 cells (28-31), suggesting their potential efficacy for the reduction of breast cancer risk.
At the mechanistic levels, the anti-proliferative effects of TNM were evidenced by induction of S-phase arrest and resultant inhibition of cell cycle progression. The pro-apoptotic effects of TNM were evidenced by the dose-dependent induction of caspase 3/7 activity. The pro-apoptotic $B A X$ and anti-apoptotic $B C L-2$ genes are critical for the mitochondrial intrinsic apoptosis (32). TNM treatment resulted in a dose-dependent increase in the expression of pro-apoptotic $B A X$ gene and decrease in the expression of anti-apoptotic $B C L-2$ gene. These data exhibiting reciprocal modulation of mRNA expression for these genes provide mechanistic leads that support the pro-apoptotic effect of TNM in the present MCF-7 ${ }^{\mathrm{AROM}}$ model. In the $\mathrm{E}_{2}$-mediated signal transduction pathways $p S 2$, GRB2 and cyclin D1 represent classical $\mathrm{E}_{2}$ responsive target genes $(11,12)$. Thus, collectively, the inhibitory effects of TNM on $\mathrm{E}_{2}$ regulated $E S R-1$ (gene for ER- $\alpha$ ), PR and AROM genes and on $\mathrm{E}_{2}$ responsive $p S 2, G R B 2$ and cyclin $D 1$ genes provide mechanistic leads relevant to possible molecular targets for the efficacy of TNM via the ER signal transduction pathways.

Long-term treatment with the pharmacological inhibitors of aromatase is frequently associated with systemic toxicity and acquired drug resistance $(2,3,6,10)$ leading to the emergence of therapy resistant stem cells. By contrast, naturally occurring TNM may exhibit lower systemic toxicity and may lack drug resistance that is induced by pharmacological inhibitors of aromatase activity. Inhibitory effect of TNM on aromatase activity is evidenced by its ability to reduce the conversion of androstenedione to $\mathrm{E}_{1}$ in MCF-7 $7^{\mathrm{AROM}}$ cells in a dose-dependent manner. The specificity of this effect is indicated by the induction of aromatase inhibition by two selective pharmacological aromatase inhibitors LET and EXM. In this context, it is noteworthy that TNM at a concentration of $4 \mu \mathrm{g}$ (NFD content: $8 \mathrm{ng}$ ) exhibits aromatase inhibition that is essentially comparable to $285 \mathrm{ng}$ of LET. Therefore, based on the NFD content of TNM, it requires 35.6-fold higher concentration of LET which is indicative of a 35.6-fold greater potency of TNM. Additionally, TNM at a concentration of $100 \mu \mathrm{g}$ (NFD content: $20 \mathrm{ng}$ ) exhibits aromatase inhibition, which is essentially comparable to 2,960 ng of EXM. Therefore, based on the NFD content of TNM, it requires 148-fold higher concentration of EXM which is indicative of a 148-fold greater potency of TNM. It is also noteworthy that extracts from natural products such as resveratrol and ellagitannin derivatives have documented anti-aromatase activity $(33,34)$. In addition, natural products such as sulforaphane, benzyl iso-thiocyanate, a vitamin A derivative all-trans retinoic acid and a terpenoid carnosol have been documented to target cancer stem cells (35-37).

The present data identified several potential mechanistic leads responsible for TNM-mediated anti-aromatase activity. For example, the clinical aromatase inhibitor LET binds the active site of the aromatase enzyme, and EXM functions as a substrate analogue for the enzyme (1). TA downregulates ESR-1 and $\mathrm{E}_{2}$ metabolizing enzymes CYP1A1 and CYP1B1 (17), and $\mathrm{ER}-\alpha$, and as its ligand $\mathrm{E}_{2}$ induces aromatase expression (38). Thus, TNM-mediated inhibition of the ER- $\alpha$ gene ESRI and of $A R O M$ raise the possibility that TNM may be effective via one or more of the mechanisms discussed above.

At present, direct evidence to support efficacy of the active principle in TNM is equivocal. However, published evidence has demonstrated anti-cancer activity of NFD in animal 
models (13). In addition to NFD, another quinone $\beta$-lapachone $(\beta$-LAP) has been documented to be present in trace amounts in the non-fractionated aqueous extracts of TA and TNM. This minor constituent, at higher pharmacological concentrations, exhibits anti-cancer activity in preclinical xeno-transplant models of epithelial organ site cancers via distinct molecular mechanisms $(15,16,39-41)$. However, it is important to recognize that at the low concentrations of TA or TNM used, the levels of $\beta$-LAP remain essentially undetectable (42).

The data from the present study have identified several potential mechanistic leads for the inhibitory efficacy of TNM in cellular models of human cancer. These leads include modulation of the RB signaling pathway, inhibition of cyclin-dependent kinase, inhibition of Cdc dual phosphatase, inhibition of cyclo-oxygenase-2, inhibition of telomerase and downregulated global expression of several genes that are involved in cell cycle progression, cellular apoptosis and hormone metabolism (14-18). Thus, collectively, these lines of evidence provide potential leads that the efficacy of TNM in the present model is likely due to its NFD content.

In conclusion, the data presented in this study, provide evidence for the growth inhibitory activity of TNM in a cellular model for aromatase-expressing post-menopausal breast cancer. More importantly, these data identify mechanistic leads as a proof of concept that TNM may be a superior naturally occurring substitute for clinical aromatase inhibitors. Overall, the present study validates an experimental approach for mechanistic evaluation of additional natural products that exhibit anti-aromatase activity. In this context, strong mechanistic leads for the efficacy of TNM in the present cell culture study identify future experimental approaches that are designed to provide clinically translatable therapeutic evidence for the use of TNM. These approaches may include experiments on the MCF-7 ${ }^{\mathrm{AROM}}$ transplant model to examine the effects of TNM on tumor progression and on molecular characteristics of tumors relevant to altered $\mathrm{E}_{2}$-mediated signal transduction pathways, Additionally, for clinical translatability of the present preclinical study, experiments to obtain clinical data on absorption, distribution, metabolism and excretion (ADME) of TNM, and on data for human safety, tolerability and efficacy of TNM may provide valuable information..

\section{Acknowledgements}

Not applicable.

\section{Funding}

Major funding support for this research was provided by Taheebo Japan, Co., Ltd. (Osaka, Japan), and by the philanthropic contributions to the American Foundation for Chinese Medicine through Randall and Barbara Smith Foundation and the Sophie Stenbeck Family Foundation.

\section{Availability of data and materials}

The data sets used and/or analyzed during the current study are available from the corresponding author on reasonable request.

\section{Authors' contributions}

NT conceived the study design, formulated the experimental protocols, and prepared the manuscript. HBN conducted all the experiments, organized and analyzed the data and participated in the preparation of the manuscript. GYCW selected the test agent and contributed to data interpretation and preparation of the manuscript. All authors have read and approved the final manuscript.

\section{Ethics approval and consent to participate}

Not applicable.

\section{Patient consent for publication}

Not applicable.

\section{Competing interests}

The authors declare that they have no competing interests.

\section{References}

1. Johnston SRD and Dowsett M: Aromatase inhibitors for breast cancer: Lessons from the laboratory. Nat Rev Cancer 3: 821-831, 2003.

2. Ali S and Coombes RC: Endocrine-responsive breast cancer and strategies for combating resistance. Nat Rev Cancer 2: 101-112, 2002.

3. Ma CX, Reinert T, Chmielewska I and Ellis MJ: Mechanisms of aromatase inhibitor resistance. Nat Rev Cancer 15: 261-275, 2015.

4. Ma CK, Gao F, Luo J, Northfeld DW, Goetz M, Forero A, Hoog J, Naughton M, Ademuyiwa F, Suresh R, et al: NeoPalAna: Neoadjuvant Palbociclib, a cyclin-dependent kinase 4/6 inhibitor, and Anastrozole for clinical stage 2 or 3 estrogen receptorpositive breast cancer. Clin Cancer Res 23: 4055-4065, 2017.

5. Taglieri L, De Iuliis F, Giuffrida A, Giantulli S, Silvestri I and Scarpa S: Resistance to the mTOR inhibitor everolimus is reversed by the downregulation of survivin in breast cancer cells. Oncol Lett 14: 3832-3838, 2017.

6. Brodie A, Jelovac D and Long BJ: Predictions from a preclinical model: Studies of aromatase inhibitors and antiestrogens. Clin Cancer Res 9: 455S-459S, 2003.

7. Boér K: Impact of palbociclib combinations on treatment of advanced estrogen receptor-positive/human epidermal growth factor 2-negative breast cancer. OncoTargets Ther 9: 6119-6125, 2016.

8. Alves CL, Elias D, Lyng M, Bak M, Kirkegaard T, Lykkesfeldt AE and Ditzel HJ: High CDK6 protects cells from Fulvestrant-mediated apoptosis and is predictor of resistance to Fulvestrant in estrogen receptor-positive metastatic breast cancer. Clin Cancer Res 22: 5514-5526, 2016.

9. Hole S, Pedersen AM, Hansen SK, Lundqvist J, Yde CW and Lykkesfeldt AE: New cell culture model for aromatase inhibitor-resistant breast cancer shows sensitivity to fulvestrant treatment and cross-resistance between letrozole and exemestane. Int J Oncol 46: 1481-1490, 2015.

10. Sabnis G and Brodie A: Understanding resistance to endocrine agents: Molecular mechanisms and potential for intervention. Clin Breast Cancer 10: E6-E15, 2010.

11. Moy B and Goss PE: Estrogen receptor pathway: Resistance to endocrine therapy and new therapeutic approaches. Clin Cancer Res 12: 4790-4793, 2006.

12. O'Hara J, Vareslija D, McBryan J, Bane F, Tibbitts P, Byrne C, Conroy RM, Hao Y, Gaora PO, Hill ADK, et al: AIB1:ER $\alpha$ transcriptional activity is selectively enhanced in aromatase inhibitor-resistant breast cancer cells. Clin Cancer Res 18: 3305-3315, 2012.

13. Ebina T: Anti-tumor effect of hot water extract of Taheebo tea: Comparison with other biological preparations. Biotherapy 16 : 321-327, 2002. 
14. Brisson M, Nguyen T, Vogt A, Yalowich J, Giorgianni A, Tobi D, Bahar I, Stephenson CR, Wipf P and Lazo JS: Discovery and characterization of novel small molecule inhibitors of human Cdc25B dual specificity phosphatase. Mol Pharmacol 66: 824-833, 2004.

15. Choi YH, Kang HS and Yoo MA: Suppression of human prostate cancer cell growth by $\beta$-lapachone via down-regulation of $\mathrm{pRB}$ phosphorylation and induction of Cdk inhibitor p21 (WAF1/CIP1). J Biochem Mol Biol 36: 223-229, 2003.

16. Lee JH, Cheong J, Park YM and Choi YH: Down-regulation of cyclooxygenase- 2 and telomerase activity by $\beta$-lapachone in human prostate carcinoma cells. Pharmacol Res 51: 553-560, 2005.

17. Mukherjee B, Telang N and Wong GYC: Growth inhibition of estrogen receptor positive human breast cancer cells by Taheebo from the inner bark of Tabebuia avellanedae tree. Int J Mol Med 24: 253-260, 2009

18. Telang NT, Nair HB and Wong GYC: Efficacy of Tabebuia avellanedae extract on a cell culture model for triple negative breast cancer. Cancer Res 74 (Suppl): SABCS, P5-14-02, 2014.

19. Liu YG, Tekmal RR, Binkley PA, Nair HB, Schenken RS and Kirma NB: Induction of endometrial epithelial cell invasion and $\mathrm{c}$-fms expression by transforming growth factor $\beta$. Mol Hum Reprod 15: 665-673, 2009

20. Livak KJ and Schmittgen TD: Analysis of relative gene expression data using real-time quantitative PCR and the 2- $\Delta \Delta C T$ method. Methods 25: 402-408, 2001.

21. Nair HB, Luthra R, Kirma N, Liu YG, Flowers L, Evans D and Tekmal RR: Induction of aromatase expression in cervical carcinomas: Effects of endogenous estrogen on cervical cancer cell proliferation. Cancer Res 65: 11164-11173, 2005.

22. American Cancer Society: Cancer facts and figures. American Cancer Society, Atlanta, GA, 2018.

23. Gupta A, Mehta R, Alimirah F, Peng X, Murillo G, Wiehle R and Mehta RG: Efficacy and mechanism of action of Proellex, an antiprogestin in aromatase overexpressing and Letrozole resistant T47D breast cancer cells. J Steroid Biochem Mol Biol 133: 30-42, 2013.

24. Panda SP, Panigrahy UP, Panda S and Jena BR: Stem extract of Tabebuia chrysantha induces apoptosis by targeting sEGFR in Ehrlich Ascites Carcinoma. J Ethnopharmacol 235: 219-226, 2019.

25. Bacowsky H: Investigations on effects of Taheebo extract on various blood parameters and quality of life in 12 patients suffering from different form of cancer in different stages. J New Rem Clin 55: 48-55, 2006.

26. Hirata S: An examination of supplement dose dependence and safety in integrative medicine for cancer: Based on the experience of Tabebuia avellanedae, a South American medicinal plant commonly known as Taheebo. Int J Integr Med 2: 140-144, 2010.

27. Lippman ME, Osborne CK, Knazek R and Young N: In vitro model systems for the study of hormone-dependent human breast cancer. N Engl J Med 296: 154-159, 1977.

28. Telang NT, Li G, Sepkovic DW, Bradlow HL and Wong GYC: Anti-proliferative effects of Chinese herb Cornus officinalis in a cell culture model for estrogen receptor-positive clinical breast cancer. Mol Med Rep 5: 22-28, 2012.
29. Telang N, Li G, Sepkovic D, Bradlow HL and Wong GYC: Comparative efficacy of extracts from Lycium barbarum bark and fruit on estrogen receptor positive human mammary carcinoma MCF-7 cells. Nutr Cancer 66: 278-284, 2014

30. Telang N, Li G, Katdare M, Sepkovic D, Bradlow L and Wong G: Inhibitory effects of Chinese nutritional herbs in isogenic breast carcinoma cells with modulated estrogen receptor function. Oncol Lett 12: 3949-3957, 2016.

31. Telang NT, Li G, Katdare M, Sepkovic DW, Bradlow HL and Wong GYC: The nutritional herb Epimedium grandiflorum inhibits the growth in a model for the Luminal A molecular subtype of breast cancer. Oncol Lett 13: 2477-2482, 2017.

32. Tait SW and Green DR: Mitochondria and cell death: Outer membrane permeabilization and beyond. Nat Rev Mol Cell Biol 11: 621-632, 2010

33. Chottanapund S, Van Duursen MB, Navasumrit P, Hunsonti P, Timtavorn S, Ruchirawat M and Van den Berg M: Anti-aromatase effect of resveratrol and melatonin on hormonal positive breast cancer cells co-cultured with breast adipose fibroblasts. Toxicol In Vitro 28: 1215-1221, 2014

34. Adams LS, Zhang Y, Seeram NP, Heber D and Chen S: Pomegranate ellagitannin-derived compounds exhibit antiproliferative and antiaromatase activity in breast cancer cells in vitro. Cancer Prev Res (Phila) 3: 108-113, 2010.

35. Castro NP, Rangel MC, Merchant AS, MacKinnon G, Cuttitta F, Salomon DS and Kim YS: Sulforphane suppresses the growth of triple negative breast cancer stem-like cells in vitro and in vivo. Cancer Prev Res (Phila) 12: 147-158, 2019.

36. Kim SH and Singh SV: Role of Krüppel-like factor4-p21 ${ }^{\mathrm{CIP} 1}$ axis in breast cancer stem-like cell inhibition by benzyl isothiocyanate. Cancer Prev Res (Phila) 12: 125-134, 2019.

37. Telang N: Targeting drug resistant stem cells in a human epidermal growth factor receptor-2-enriched breast cancer model. World Acad. Sci. J. 1: 86-91, 2019.

38. Kinoshita Y and Chen S: Induction of aromatase (CYP19) expression in breast cancer cells through a nongenomic action of estrogen receptor $\alpha$. Cancer Res 63: 3546-3555, 2003.

39. Woo HJ and Choi YH: Growth inhibition of A549 human lung carcinoma cells by $\beta$-lapachone through induction of apoptosis and inhibition of telomerase activity. Int J Oncol 26: 1017-1023, 2005.

40. Jeon YJ, Bang W, Shin JC, Park SM, Cho JJ, Choi YH, Seo KS, Choi NJ, Shim JH and Chae JI: Downregulation of Sp1 is involved in $\beta$-lapachone-induced cell cycle arrest and apoptosis in oral squamous cell carcinoma. Int J Oncol 46: 2606-2612, 2015.

41. Bang W, Jeon YJ, Cho JH, Lee RH, Park SM, Shin JC, Choi NJ, Choi YH, Cho JJ, Seo JM, et al: Shim JH ad Chae JI: $\beta$-lapachone suppresses the proliferation of human malignant melanoma by targeting specificity protein 1. Oncol Rep 35: 1109-1116, 2016.

42. Queiroz ML, Valadares MC, Torello CO, Ramos AL, Oliveira AB, Rocha FD, Arruda VA and Accorci WR: Comparative studies of the effects of Tabebuia avellanedae barh extract and $\beta$-lapachone on hematopoietic response of tumor bearing mice. J Ethnopharmacol 117: 228-235, 2008. 